\title{
Study of effect of process parameter setting on porosity levels of aluminium pressure die casting process using Taguchi Methodology
}

\author{
Kulkarni Sanjay Kumar ${ }^{1}$, J K Sawale ${ }^{2}$, Sampath Rao ${ }^{3}$ \\ 1,3 Department of Mechanical Engineering, VREC College Nizamabad, JNTU HYD, India \\ ${ }^{2}$ Department of Mechanical Engineering, MGM's College, SRTMU NND, India
}

\begin{abstract}
This paper discusses the study and examined effect of die casting process parameters on porosity in aluminium alloy SAE 308 by using Taguchi method. In any die casting industry porosity is a very serious problem faced by production department and also being an invisible defect it is not identified visually in running production. It is shown in this work that die casting parameters which are related with machine such as first phase speed, second phase speed, first phase length and injection pressure all have significant influence on porosity level. The quality assessment of the die casting part was based on porosity measurement. The experiment have been performed as per the combination of levels of different process parameters suggested by L9 orthogonal array and conformation experiments have been performed to validate the optimum levels of different parameters
\end{abstract}

Keywords: Aluminum casting, die casting, Taguchi Methodology, Design of Experiments, orthogonal array

\section{Introduction}

Pressure Die Casting Process (PDC) is a complex industrial system. In a typical die casting machine the molten metal is poured in the shot sleeve through a ladle after the die is closed. A movement of plunger (piston) forces the metal through the die resulting in that the moveable part coincides with the fixed part. Some die casting machines allow for this plunger movement to be completed in four stages. However, typically it is done in two stages only. The plunger starts initially with a low velocity, then the velocity increases during the piston's motion at a change over position, the length of travel of the piston in the low velocity up to the change over point is known as first phase length and the injection pressure is decreases at the end when nearly all the liquid metal is injected into the die and solidifies.. During this process taking place inside the shot sleeve the flow of the metal inside the shot sleeve before plunger should be in laminar if these speeds, first phase length, and injection pressure are not set properly the flow of metal will disturbed and convert into turbulence and there will be possibility of formation of porosity during process [7]. Though die casting process has a large number of parameters that may affect the quality of the casting some of these are controllable while others are noise factors. Therefore, a die casting company can be an ideal place to apply Taguchi's test method for continuous and rapid quality improvement. In this experiment more importance is given for the parameter design stage. The basic steps to investigate the role process parameters in porosity formation and to improve casting quality are summarized below.

1. Determine the casting porosity as a quality characteristic

2. Select the most significant die casting parameters that cause variation in porosity.

3. Operate the die casting process under the experimental conditions dictated by the chosen L9 orthogonal array (OA) and parameter levels. Collect data.

4. Analyses the data. An analysis of variance (ANOVA) table can be generated to determine the statistical significance of the parameters. Response graphs are plotted to determine preferred levels of each parameter.

5. Make decisions regarding optimum setting of control parameters.

6. Predict the treatment casting porosity conditions that derive from the new optimum level of each parameter

\section{Experimental procedure}

In this experiment the die casting cell consists of $250 \mathrm{~T}$ die casting machine, a holding furnace, an automatic lubrication for inner die surfaces, an automatic metal ladle, robot extractor and shot monitoring system for analysis and investigation of different die casting parameters. The test component is a irregular shape connecting rod part shown in Fig.1. 


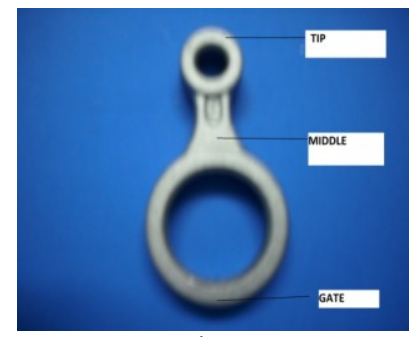

Fig.1

Also percentage porosity was the primary quantitative measure in this investigation; the first step was the accurate determination of sample density by immersion technique. All samples were weighed twice to check the error and for repeatability of results on electronic weighing machine in grams. Volume of sample was calculated by Archimedes principle that is volume of the water that solid displace when it is immersed in the water is the same as the volume of the solid itself. The density was calculated by mass/volume for each sample. Porosity was calculated by using relation [3] (1)

$$
\operatorname{Porosity}(\%)=\left(1-\frac{\rho_{s}}{\rho_{o}}\right) \times 100
$$

Where $\rho_{S}$ is the measured casting density and $\rho_{o}$ is the fully dense casting having no porosity $\left(3.25 \mathrm{~g} / \mathrm{cm}^{3}\right)$. Porosity is a type of quality characteristic with the objective 'the lower the better'. Therefore the $S / N$ ratio was used for this of response and is given by [3] (2)

$$
S / N=-10 \log \left(\frac{1}{n} \sum_{i=1}^{n} D_{i}^{2}\right)
$$

The most significant parameters were selected are first phase speed as (factor A), second phase speed as (factor B), first phase length as (factor C), Injection pressure as (factor D). The other parameters are kept constant for entire experimentation. The selected process parameters, along with their ranges are given in Table1 The most significant parameters were selected are first phase speed as (factor A), second phase speed as (factor B), first phase length as (factor C), Injection pressure as (factor D). The other parameters are kept constant for entire experimentation. The selected process parameters, along with their ranges are given in Table1

Table1. Process parameters with their ranges and value at three levels

\begin{tabular}{llccc}
\hline $\begin{array}{l}\text { Parameter } \\
\text { designation }\end{array}$ & \multicolumn{1}{c}{ Process Parameters } & Range & Level 1 & Level 2 \\
\hline A & First Phase Speed $(\mathrm{m} / \mathrm{s})$ & $0.25-0.87$ & 0.25 & 0.56 \\
B & Second Phase Speed $(\mathrm{m} / \mathrm{s})$ & $1.05-2.25$ & 1.05 & 1.65 \\
$\mathrm{C}$ & First phase length $(\mathrm{mm})$ & $185-250$ & 185 & 2.25 \\
$\mathrm{D}$ & Injection Pressure $\left(\mathrm{kg} / \mathrm{cm}^{2}\right)$ & $220-270$ & 220 & 250 \\
\hline
\end{tabular}

In this study an L9 orthogonal array with five columns and nine rows was used. This array has eight degree of freedom and it can handle four process parameter. Each die casting parameter was assigned to a column and nine die casting parameter combinations were tested. Therefore only nine experiments are required to study the entire casting parameter space using the L9 orthogonal array. The experimental layout for the casting parameters using L9 orthogonal array is shown in Table $3[12,13,14]$ 
Table 3 L9 Experimental Combination

\begin{tabular}{|c|c|c|c|c|}
\hline Expt no & $\begin{array}{lll}\text { First phase speed } \\
(\mathrm{m} / \mathrm{s}) & \text { A } & \end{array}$ & $\begin{array}{l}\text { Second phase speed } \\
(\mathrm{m} / \mathrm{s}) \\
\mathrm{B}\end{array}$ & $\begin{array}{l}\text { First phase length }(\mathrm{mm}) \\
\text { C }\end{array}$ & $\begin{array}{l}\text { Injection pressure }\left(\mathrm{kg} / \mathrm{cm}^{2}\right) \\
\mathrm{D}\end{array}$ \\
\hline 1 & 0.25 & 1.05 & 185 & 220 \\
\hline 2 & 0.25 & 1.65 & 217 & 245 \\
\hline 3 & 0.25 & 2.25 & 250 & 270 \\
\hline 4 & 0.56 & 1.05 & 217 & 270 \\
\hline 5 & 0.56 & 1.65 & 250 & 220 \\
\hline 6 & 0.56 & 2.25 & 185 & 245 \\
\hline 7 & 0.87 & 1.05 & 250 & 245 \\
\hline 8 & 0.87 & 1.65 & 185 & 270 \\
\hline 9 & 0.87 & 2.25 & 217 & 220 \\
\hline
\end{tabular}

Table 4. Casting porosity values and $\mathrm{S} / \mathrm{N}$ ratios against trial numbers

Porosity Rating Results
Cntrol Factors

\begin{tabular}{|c|c|c|c|c|c|c|c|c|c|c|}
\hline Ext No & A & B & $\mathrm{C}$ & $\mathrm{D}$ & Sample 1 & Sample 2 & Sample 3 & Average & S.D & $\begin{array}{l}\text { S/N Ratio } \\
(\eta) \mathrm{dB}\end{array}$ \\
\hline 1 & 1 & 1 & 1 & 1 & 0.210 & 0.203 & 0.197 & 0.203 & 0.007 & -13.833 \\
\hline 2 & 1 & 2 & 2 & 2 & 0.171 & 0.168 & 0.170 & 0.170 & 0.002 & -15.411 \\
\hline 3 & 1 & 3 & 3 & 3 & 0.168 & 0.167 & 0.167 & 0.167 & 0.001 & -15.534 \\
\hline 4 & 2 & 1 & 2 & 3 & 0.176 & 0.170 & 0.171 & 0.172 & 0.003 & -15.275 \\
\hline 5 & 2 & 2 & 3 & 1 & 0.176 & 0.176 & 0.179 & 0.177 & 0.002 & -15.047 \\
\hline 6 & 2 & 3 & 1 & 2 & 0.170 & 0.179 & 0.170 & 0.173 & 0.005 & -15.243 \\
\hline 7 & 3 & 1 & 3 & 2 & 0.176 & 0.175 & 0.180 & 0.177 & 0.003 & -15.044 \\
\hline 8 & 3 & 2 & 1 & 3 & 0.178 & 0.184 & 0.177 & 0.180 & 0.004 & -14.921 \\
\hline 9 & 3 & 3 & 2 & 1 & 0.178 & 0.185 & 0.179 & 0.181 & 0.004 & -14.867 \\
\hline
\end{tabular}

$\mathrm{M}=0.177$ is overall mean porosity. The bold numbers for Experiment No 1 and 3 represents the max and min porosity values. The overall mean value of $\eta$ for the experiment region defined by factor levels in table 4 as [23] (6)

$m=\frac{1}{9} \sum_{n=9}^{9} \eta_{i}=\frac{1}{9}\left(\eta_{1}+\eta_{2}+\cdots \cdots+\eta_{9}\right)=-15.019 d B$

Using the $\mathrm{S} / \mathrm{N}$ ratio data and porosity data available in Table 4 the average of each level of the four factors is calculated and listed in Table 5 and 6 . They are the separate effect of each factor and are commonly called main effects. The Graph 1. Shows the relations between the factors of A, B, C, D and the porosity levels (average effect response for porosity levels)

Table 5. Average effect response for $\mathrm{S} / \mathrm{N}$ ratio $(\eta) \mathrm{dB}$

\begin{tabular}{lcccc}
\multicolumn{5}{c}{ Table 5. Average effect response for S/N ratio $(\eta) \mathrm{dB}$} \\
\hline LEVELS & $\mathrm{A}$ & $\mathrm{B}$ & $\mathrm{C}$ & $\mathrm{D}$ \\
1 & -14.926 & -14.717 & -14.665 & -14.582 \\
2 & -15.188 & -15.126 & -15.184 & -15.232 \\
3 & -14.944 & -15.214 & -15.203 & -15.243 \\
MAX-MIN & 0.262 & 0.497 & 0.538 & 0.661 \\
RANK & 4 & 3 & 2 & 1
\end{tabular}

MAX - MAXIMUM VALUE IN THE CORRESPONDING COLUMN MIN - MINIMUM VALUE IN CORRESPONDING COLUMN

Table 6. Average effect response for casting porosity

\begin{tabular}{lcccc}
\hline LEVELS & $\mathrm{A}$ & $\mathrm{B}$ & $\mathrm{C}$ & $\mathrm{D}$ \\
1 & 0.18 & 0.184 & 0.185 & 0.187 \\
2 & 0.174 & 0.175 & 0.174 & 0.173 \\
3 & 0.179 & 0.173 & 0.173 & 0.173 \\
MAX-MIN & 0.006 & 0.011 & 0.012 & 0.014 \\
RANK & 4 & 3 & 2 & 1
\end{tabular}

MAX - MAXIMUM VALUE IN THE CORRESPONDING COLUMN

MIN - MINIMUM VALUE IN CORRESPONDING COLUMN 

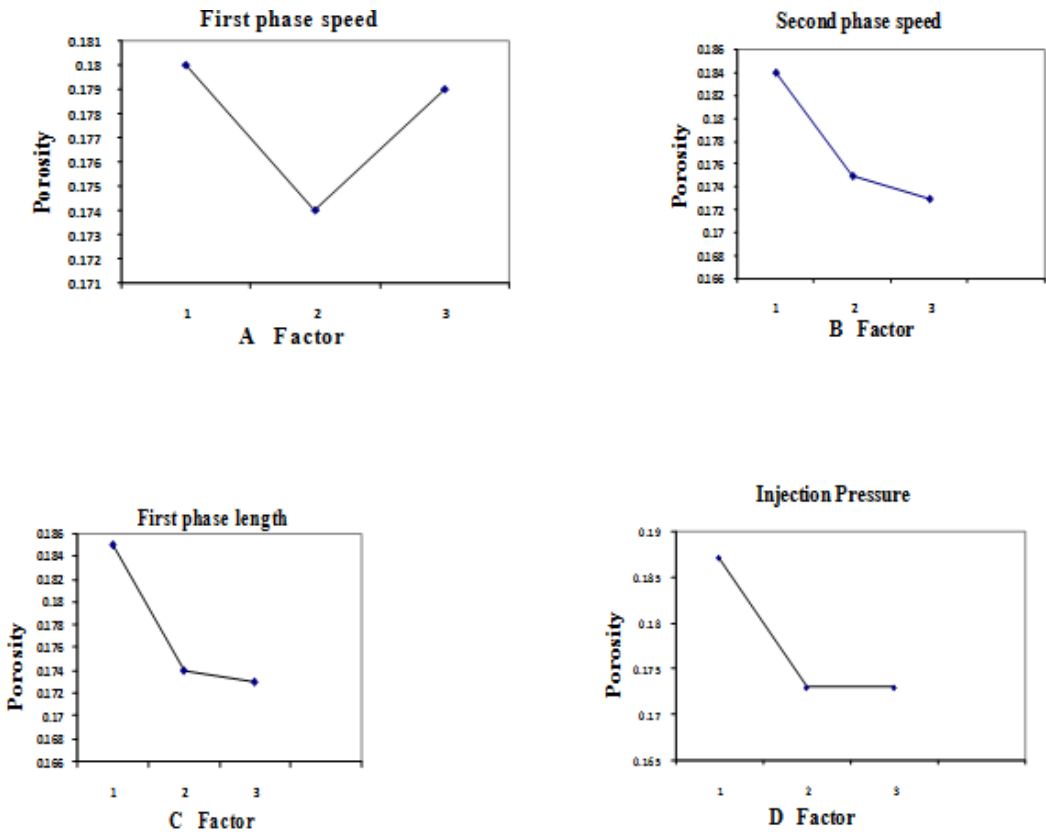

The next step is the analysis of variance (ANOVA). The relative magnitude of the factor effects are listed in Table 7 and 8. A better feel for the relative effect of the different factors is obtained by the decomposition of variance, which is commonly called as analysis of variance (ANOVA). This is obtained first by computing the sum of squares. [12] (11) (12) (13) (14)

Total sum of squares $=\sum_{i=1}^{9} \eta_{i}^{2}=\left(\eta_{1}^{2}+\eta_{2}^{2}+\cdots \cdots+\eta_{9}^{2}\right)$

Sum of squares due to mean $=($ number of experiments $) \times \mathrm{m}^{2}$

Total Sum of squares and mean difference $=\sum_{i=1}^{9}\left(\eta_{i}-m\right)^{2}$

Sum of the squares due to factor $\mathrm{A}$

$=\left[\left(\right.\right.$ number of experiments at level $\left.\mathrm{A}_{1}\right) \times\left(\mathrm{m}_{\mathrm{A} 1}-\mathrm{m}\right)^{2}+$

(number of experiments at level $\left.\mathrm{A}_{2}\right) \times\left(\mathrm{m}_{\mathrm{A} 2}-\mathrm{m}\right)^{2}+$

(number of experiments at level $\left.\left.\mathrm{A}_{3}\right) \times\left(\mathrm{m}_{\mathrm{A} 3}-\mathrm{m}\right)^{2}\right]$

Similarly the sum of squares due to factor B,C and D can be computed as respectively. Now all these sun of squares are tabulated in Table 7 due to $\mathrm{S} / \mathrm{N}$ ratio and in Table 8 due to porosity values. The contribution percentage of all the four parameters has been estimated.

Table7. S/N ratio of casting porosity pooled ANOVA

\begin{tabular}{lllllll}
\hline FACTOR & $\begin{array}{l}\text { DEGREE } \\
\text { FREEDOM }\end{array}$ & OF & $\begin{array}{l}\text { SUM } \\
\text { SQUARES }\end{array}$ & $\begin{array}{l}\text { OF } \\
\text { OFAN SQUARE = SUM } \\
\text { OF FREERE/ }\end{array}$ & F - RATIO & P×100 \% \\
A & 2 & $0.128501^{*}$ & 0.0642525 & 0.466 & 6.5 \\
B & 2 & $0.422034 *$ & 0.211017 & 1.533 & 21.43 \\
C & 2 & 0.559191 & 0.2795955 & 2.031 & 28.39 \\
D & 2 & 0.85954 & 0.429 & 3.122 & 43.64 \\
TOTAL & 8 & 0 & 0 & & 100.00 \\
(ERROR)POOL & 4 & 1.969266 & 1.969266 & & \\
\hline
\end{tabular}

Table 8. Casting porosity pooled ANOVA

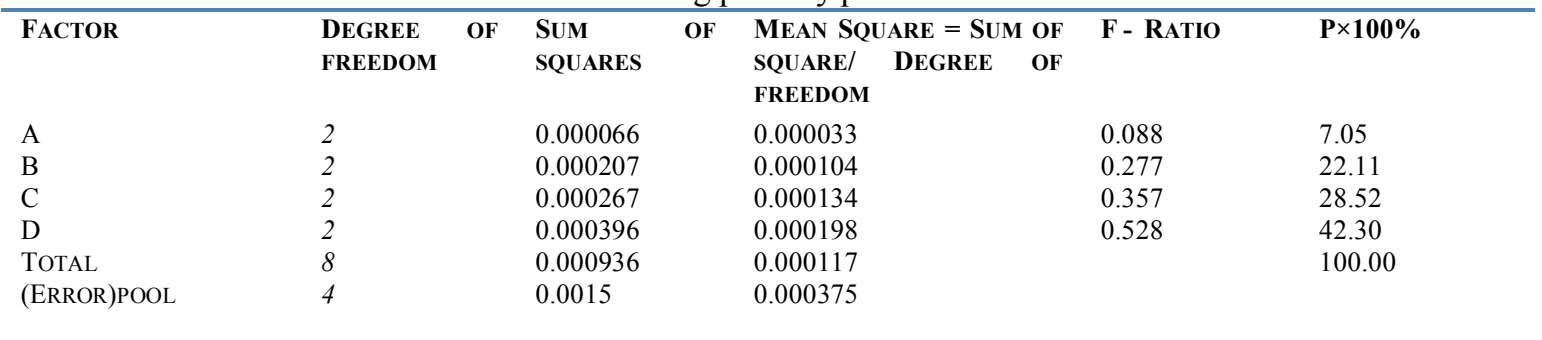

In order to study the parameter significance, ANOVA was performed in Table 7 of the $\mathrm{S} / \mathrm{N}$ ratio. From Table 7 it is seen that the injection pressure (parameter D) significantly affect the mean average of $\mathrm{S} / \mathrm{N}$ ratio of 43.64\%. Also, the first phase speed (parameter A), second phase speed (Parameter B) and first phase length 
(parameter $\mathrm{C}$ ) affect $\mathrm{S} / \mathrm{N}$ ratio of $6.5,21.43,28.39$, percentage respectively. Table 8 presents an ANOVA of mean average casting porosity for same parameters. From Table 8 it is proved that the same parameters (A, B, C and D) significantly affect the variability in $\mathrm{S} / \mathrm{N}$ ratio of $7.05,22.11,28.52$, and 42.30 percentage respectively.

\section{Estimation of predicted mean}

At the optimum setting condition, the casting porosity values were estimated from the following equation.[3](3) (3) (5)

Predicted casting porosity:

$\hat{\mu}=M \times \beta(M)+\left(A_{3}-M\right) \times \beta(A)+\left(B_{3}-M\right) \times \beta(B)+\left(C_{3}-M\right) \times \beta(C)$

$+\left(D_{3}-M\right) \times \beta(D)$

$\beta(P)=1-\frac{1}{F_{p}}$

Where $\mathrm{F}_{\mathrm{p}}$ is the $\mathrm{F}$ - ratio of factor $\mathrm{P}$. parameters $A_{3}, B_{3}, C_{3}, \& D_{3}$ represent the best condition of experiments. The $\beta(M)$ is the overall $\beta$ - factor which is defined as $\beta(M)=1-\frac{v_{q}}{\tau}$

Where $\mathrm{T}$ is the sum square (ss) and $v_{\varepsilon}$ is the variance due to error. From Tables 3 to 8 it can be represented that $\mathrm{M}=0.177$ percentage for casting porosity.

$\mathrm{T}=0.000936$ and $v_{e}=0.000375$. Therefore, the predicted mean estimation of casting porosity is calculated $\hat{\mu}=0.0625$

\section{Estimation of predicted confidence interval}

Confidence interval (CI) of the above predicted estimation can be calculated taking into account the following equation [24]

$\mathrm{CI}=\sqrt{\frac{F_{\alpha}, v_{1}, v_{2}, v_{e}}{n_{e f f}}}$

Where $F_{\alpha}, v_{1}, v_{2}=$ F ratio

$\alpha=$ risk (0.05) $\quad$ confidence $=1-\alpha$. Therefore for the casting porosity the confidence interval is $95 \%$

$v_{1}=d o f$ for mean which is always $=1$

$v_{2}=$ dof for error, $v_{\theta}=0.000375$

$n_{\text {eff }}=$ number of testes under that condition using the participating factors.

$n_{\text {eff }}=\frac{9}{1+\operatorname{dof}(A, B, C, D)}=\frac{9}{1+2+2+2+2}=1$

$\mathrm{CI}= \pm \sqrt{\frac{0.05 \times 1 \times 4 \times 0.000375}{1}}=0.00866$

Therefore the confidence interval is computed as $\mathrm{CI}=0.00866$. The 95 percentage confidence interval of the predicted optimum is

$[\mu-\mathrm{CI}]<\mu<[\mu+\mathrm{CI}] \quad \approx 0.05385<0.0625<0.07116$

\section{Confirmation Experiments}

Three confirmation tests were conducted at the optimum setting of the process parameters as recommended by the investigation. The average value of casting porosity obtained at the optimum setting of die casting parameters was found to be within the predicted confidence interval of the casting porosity.

\section{Conclusion}

The following conclusions were drawn from the present investigation. The experimental procedure showed that the first phase speed, second phase sped, first phase length and injection pressure are the influential parameters affecting the casting porosity ally SAE 308. Consequently the higher level of injection pressure 270 $\mathrm{kg} / \mathrm{cm}^{2}$ has the most significant effecting. This was expected because the injection pressure stage of the die casting procedure is more significant than others, as confirmed by literature and experimentation. The predicted mean estimation of casting porosity was calculated as 0.0625 percentages with a confidence interval of 
between 0.05384 and 0.0 .07116 percentages. The results are valid within the above range of process parameters and for the specified SAE 308 alloy casting.

\section{Acknowledgements}

The authors wish to thank Tyche die Cast Company for the use of its industrial installations and equipments.

\section{References}

[1] R.Monroe, Porosity in Casting, AFS Transactions American Foundry Society 2005

[2] Y.J. Huang, B.H. Hu, I. Pinwill, W.Zhou \& D.M.R Taplin. Effects of process settings on the porosity levels of AM60B magnesium die castings : Materials and Manufacturing, 2009.

[3] K S Anastasiou, optimization of the aluminium die casting process based on the taguchi method. Journal of Engineering Manufacture June 3, 2011

[4] A.Nouri-Borujerdi, Analysis of vacuum venting in Die Casting: SCIENTIA IRANICA, October 2004.

[5] S.Thanabumrungkul, S.Janudom, R.Burapa. Industrial development of gas induced semi-solid process: Transactions of Nonferrous Metals Society of China: 25 June 2010.

[6] S.Thanabumrungkul, S.Janudom, R.Burapa. Industrial development of gas induced semi-solid process: Transactions of Nonferrous Metals Society of China: 25 June 2010.

[7] Imran Khan, YakovFrayman and Sacid Nahavandi: Modelling of porosity defects in high pressure die casting with a neural network. Journal of Materials Processing Technology, 2009.

[8] Drd. Ing, sorina Moica: Taguchi Experiment to establish the Process Parameters for Die Cast Aluminum Parts: Journal of interengineering 2009

[9] G.O. Verran: DOE applied to optimization of aluminum alloy die castings: Journal of Materials Processing Technology 13 Aug 2007.

[10] Satish Kumar, Arun Kumar Gupta, Pankaj Chandna: Optimization of Process Parameters of Pressure Die Casting using Taguchi Methodology: International Journal of Mechanical and Industrial Engineering 2012

[11] D.R. Gunasegarama,, D.J. Farnsworthb,1, T.T. Nguyena, Identification of critical factors affecting shrinkage porosity in permanent mold casting using numerical simulations based on design of experiments

[12] Approch of Robust Design - IIT Bombay

[13] Lalit kumar, Thesis on Multi- Response optimization of process parameters in cold chamber pressure die casting, Thapar university Patiala July 2010

[14] P.Vijian, V P Arunachalam \& S. Charles, Study of surface roughness in squeeze casting LM6 aluminium alloy using Taguchi Method 